\title{
Indomethacin Does Not Alter the Circulating Catecholamine Response to Asphyxia in the Neonatal Piglet
}

\author{
ROBERT S. GREEN, CHARLES W. LEFFLER, DAVIS W. BUSIJA, ANTHONY M. FLETCHER, \\ AND DONATHAN G. BEASLEY
}

The University of Tennessee, Memphis, Departments of Physiology and Biophysics, Pediatrics [R.S.G.], and Obstetrics and Gynecology [R.S.G.], Memphis, Tennessee 38163

\begin{abstract}
The response of circulating catecholamines to asphyxia in unanesthetized, spontaneously breathing neonatal piglets was measured before and after treatment with indomethacin. Prior to treatment with indomethacin, baseline levels [geometric mean, $\mathrm{pg} / \mathrm{ml}$ (95\% confidence limits)] of $\mathrm{D}, \mathrm{E}$, and $\mathrm{N}$ were 162 (99-266), $174(52-579)$, and $380(286-506)$, respectively. Inhalation of $10 \% \mathrm{O}_{2} / 9 \%$ $\mathrm{CO}_{2}$ for $20 \mathrm{~min}$ caused significant increases in arterial levels of all three catecholamines to $389(230-659,1514$ (993-2306), and $3802(2731-5293)$, respectively. Treatment with indomethacin $(5 \mathrm{mg} / \mathrm{kg}$, intravenous) did not significantly alter either baseline levels of the catecholamines or the levels after $\mathbf{2 0}$ min of the asphyxiating gas. In time control piglets, baseline levels and the response to asphyxia were similar before and after placebo. These results suggest that the circulating catecholamine response to asphyxia of the neonatal piglet is independent of the prostaglandin system. (Pediatr Res 21: 534-537, 1987)
\end{abstract}

\section{Abbreviations}

$\mathrm{PGE}_{2}$, prostaglandin $\mathrm{E}_{2}$

IND, indomethacin

E, epinephrine

PGI 2 , prostaglandin $I_{2}$

$D$, dopamine

$\mathrm{N}$, norepinephrine

Prostanoids (1) and catecholamines (2) are potential modulators of neonatal circulatory and metabolic function under normal conditions and in response to stress. There is evidence suggesting an interdependence of the control of prostanoid and catecholamine release in various organs. For example, in several organ systems in the adult the release of $\mathrm{N}$ from adrenergic nerve endings in response to nerve stimulation is augmented by IND (3). This augmentation is believed to be due to inhibition of a putative prostaglandin-mediated negative feedback loop which modulates sympathetic neurotransmission in vascular smooth muscle. Furthermore, adrenal release of catecholamines also may be augmented by IND (4).

Increased circulating levels of catecholamines are important

Received March 19, 1986; accepted December 24, 1986

Reprint requests Robert S. Green, M.D., Newborn Center, 853 Jefferson Avenue, Room 201, Memphis, TN 38163.

Supported in part by grants in aid from the National Institutes of Health, the American Heart Association, the Tennessee Heart Association, and a Program Project Grant from the National Institutes of Health. C.W.L. is an Established Investigator of the American Heart Association. in the newborn's adaptation to a variety of stimuli such as asphyxia, including the events of normal labor and delivery (5). Circulating prostaglandin levels are increased in the newborn compared to the older child and adult (6), and activation of the prostaglandin system in several organs is an important part of the neonatal response to asphyxia (7-9). Thus, interaction of the catecholamine and prostanoid systems in the neonatal period would be significant both because it could be important in the circulatory and metabolic adjustments to asphyxia and because agonists and antagonists of both of these systems are in common use clinically $(10-12)$.

In the present study we test the hypothesis that inhibition of prostanoid synthesis with IND augments the response of circulating catecholamines to asphyxia in neonatal piglets.

\section{METHODS}

Animal preparation. Fifteen piglets [3-5 days old at time of study; weight $1.14 \pm 0.32$ (SD) kg] were used in this study. Nine of these piglets (six IND, three placebo) were instrumented under general anesthesia 3 days prior to the experiment as described previously (8). The remaining six piglets (three IND, three placebo) were instrumented acutely under local femoral anesthesia on the day of the experiment and allowed to recover for $2 \mathrm{~h}$ prior to being studied. Results from piglets instrumented by these two methods give similar conclusions. Arterial and venous catheters were placed in all animals for monitoring blood pressure, sampling arterial blood, and administering drug. All studies were carried out with the piglets unanesthetized, spontaneously breathing, and quiet. Inspired gases were controlled by placing the piglet's head in a bag through which passed either room air or the asphyxiating gas mixture $\left(10 \% \mathrm{O}_{2}, 9 \% \mathrm{CO}_{2}\right.$, balance nitrogen). Rectal temperature was monitored continuously and maintained at $100 \pm 1^{\circ} \mathrm{F}$ using a heating pad and/or heat lamps throughout the study. The last feeding prior to an experiment was no more than $30 \mathrm{~min}$ before the beginning of the study, and the piglets had free access to formula during the two-h break described below.

Experimental protocol. With the piglets breathing room air, baseline arterial pressure was measured, and samples for catecholamine determination $(1.0 \mathrm{ml})$ and arterial blood gases and $\mathrm{pH}(0.3 \mathrm{ml})$ were drawn (sample 1$)$. The inspired gas mixture was then changed to the asphyxiating gas for $20 \mathrm{~min}$, at which time repeat arterial pressure determination and blood sampling were performed (sample 2). The animals then received intravenously either $5 \mathrm{mg} / \mathrm{kg}$ IND in $5 \mathrm{ml}$ of normal saline (treatment animals, $n=9$ ) or $5 \mathrm{ml}$ of saline with no drug (placebo-time control animals, $n=6$ ). Two hours, with the piglets breathing room air and having free access to formula, was then allowed for catecholamines to return to baseline and for prostanoid synthesis 
inhibition to occur in those animals who received IND. We previously have shown (8) that this regimen of IND administration results in essentially complete cyclooxygenase inhibition. After this 2-h rest period, arterial pressure determination and blood sampling were performed with the piglets breathing room air (sample 3). Then, the piglets breathed the asphyxiating gas for $20 \mathrm{~min}$, at the conclusion of which a final pressure determination and blood sampling were done (sample 4).

Arterial blood pressure was monitored using a pressure transducer and recorded continuously on a physiologic recorder. Arterial $\mathrm{PO}_{2}, \mathrm{PCO}_{2}$, and $\mathrm{pH}$ were determined using a standard clinical blood gas machine.

Catecholamine assay procedure. Plasma concentrations of $\mathrm{N}$, $\mathrm{E}$, and $\mathrm{D}$ were determined employing a radioenzymatic assay (13). Briefly, the catecholamines were converted to tritiated derivatives by using the enzyme carboxy-o-methyl-transferase to catalyze the transfer of a tritiated methyl group from S-adenosylL-methionine to the meta-hydroxyl group on the ring of the original compounds. The resulting products were purified by extraction and thin-layer chromatography and quantified using a scintillation counter. Reagents were obtained in the commercially available Cat-a-Kit (Upjohn Diagnostics, Kalamazoo, MI).

Data analysis. Prior to statistical analysis, values for catecholamines were converted to the log of the plasma concentration expressed in $\mathrm{pg} / \mathrm{ml}$ as described previously (14). Results of the catecholamine concentrations are reported as geometric means (95\% confidence limits). This logarithmic transformation and the use of the geometric means were employed because the log of the catecholamine concentration is more nearly normally distributed than are the absolute concentrations. The log catecholamine concentrations, $\mathrm{pH}$, blood gases, and blood pressures in both the treatment and time control groups were compared using a two-way analysis of variance for a randomized block factorial $2 \times 2$ (drug versus no drug $\times$ asphyxia versus normal) design (15). Significant difference was defined as $p<0.05$.

\section{RESULTS}

The results of the catecholamine determinations in the treatment group are shown in Figure 1. Prior to treatment with IND, baseline geometric mean (95\% confidence limits) values in $\mathrm{pg} /$ $\mathrm{ml}$ were 162 (99-226) for $\mathrm{D}, 174$ (52-579) for E, and $380(286-$ 506) for $\mathrm{N}$. After $20 \mathrm{~min}$ of breathing $10 \% \mathrm{O}_{2} / 9 \% \mathrm{CO}_{2}$, these values had increased to 389 (230-659) for D, 1514 (993-2306) for $\mathrm{E}$, and 3802 (2731-5293) for N. After IND treatment, baseline values were 155 (84-287) for D, $129(39-423)$ for $E$, and 331 (181-604) for $\mathrm{N}$. The repeat challenge with $10 \% \mathrm{O}_{2} / 9 \% \mathrm{CO}_{2}$ after IND again resulted in a rise in levels to $646(338-1233)$ for D, 1995 (846-4703) for E, and 6607 (2679-16293) for N. The analysis of variance revealed a significant effect of the asphyxiating gas on all three catecholamines $\left(\mathrm{F}_{1 / 24}=28.2,55.7\right.$, and 93.2 for $\mathrm{D}, \mathrm{E}$, and $\mathrm{N}$, respectively; $p<0.001$ for all three). However, there was no significant effect of IND $\left(F_{1 / 24}=1.1,0.0,0.6\right.$, respectively) and no significant interaction of the effects of the asphyxiating gas and IND $\left(F_{1 / 24}=1.7,0.8\right.$, and 1.5 , respectively) on any of the three catecholamines. Thus, inhalation of $10 \% \mathrm{O}_{2}$ / $9 \% \mathrm{CO}_{2}$ caused a significant increase in all three catecholamines; however, IND had no effect on either baseline levels or the response to the asphyxiating gas for any of the three catecholamines.

In the time control group (Fig. 2), $10 \% \quad \mathrm{O}_{2} / 9 \% \quad \mathrm{CO}_{2}$ caused a significant increase in all three catecholamines both before and after placebo. As expected, placebo had no effect on either baseline values or the response to the asphyxiating gas.

Results of $\mathrm{pH}$, blood gases, and blood pressure determinations are shown in Table 1. The asphyxiating gas caused a similar degree of hypoxia, hypercapnia, and acidosis before and after the drug in both the IND and placebo-time control groups. In the placebo-time control group, both baseline and asphyxial $\mathrm{PO}_{2}$ values were slightly lower during the second period than during

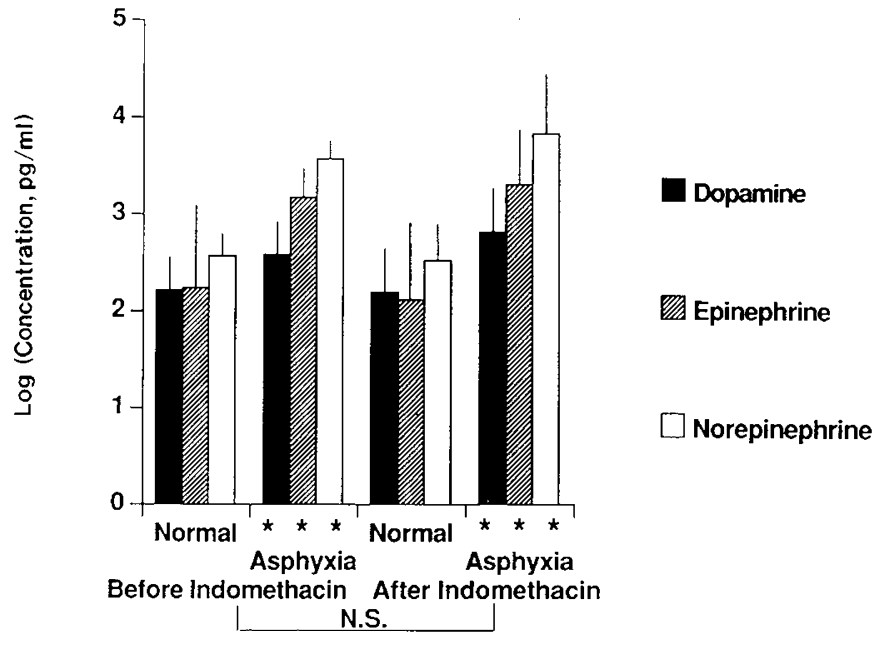

Fig. 1. Arterial levels of catecholamines in neonatal piglets $(n=9)$ breathing room air (normal) or $10 \% \mathrm{O}_{2} / 9 \% \mathrm{CO}_{2}$ (asphyxia) before and $2 \mathrm{~h}$ after $5 \mathrm{mg} / \mathrm{kg}$ indomethacin. Error bars indicate $1 \mathrm{SD}$. Asterisk indicates asphyxia values significantly different from normal values. $N S$ indicates no significant difference of values before and after indomethacin.

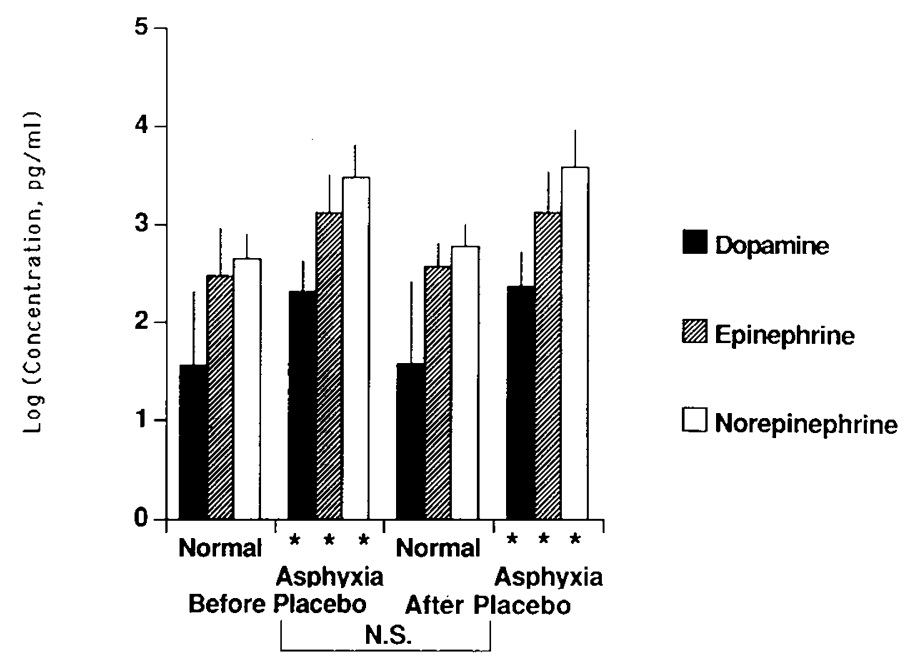

Fig. 2. Arterial levels of catecholamines in neonatal piglets $(n=6)$ breathing room air (normal) or $10 \% \mathrm{O}_{2} / 9 \% \mathrm{CO}_{2}$ (asphyxia) before and $2 \mathrm{~h}$ after placebo. Error bars indicate $1 \mathrm{SD}$. Asterisk indicates asphyxia values significantly different from normal values, NS indicates no significant difference of values before and after placebo.

the first; however, there was no significant difference in the asphyxiating gas-induced decrement in $\mathrm{PO}_{2}$ between these two periods, as is indicated by the absence of interaction in the analysis of variance.

In the IND group, both before and after the drug, asphyxia caused a significant increase in mean arterial pressure; this blood pressure increase was not altered by IND. Although there was a trend to increase blood pressure with asphyxia in the placebotime control group, this was not significant.

\section{DISCUSSION}

In the present study, we found marked elevations in the levels of circulating catecholamines in neonatal piglets after breathing $10 \% \mathrm{O}_{2} / 9 \% \mathrm{CO}_{2}$ for $20 \mathrm{~min}$. However, IND did not alter either the baseline levels of the catecholamines or the response to the asphyxiating gas.

Results of arterial $\mathrm{N}$ and $\mathrm{E}$ levels measured after moderate stress in the perinatal period in other species are similar to those 
GREEN ET $A L$.

Table 1. Arterial blood gases, $p H$, and blood pressure (values are mean $\pm S D$ )

\begin{tabular}{|c|c|c|c|c|c|c|c|}
\hline & \multicolumn{2}{|c|}{ Before drug } & \multicolumn{2}{|c|}{ After drug } & \multicolumn{3}{|c|}{ Results of analysis of variance } \\
\hline & $\begin{array}{c}\text { Sample } 1 \\
\text { normal }\end{array}$ & $\begin{array}{l}\text { Sample } 2 \\
\text { asphyxia }\end{array}$ & $\begin{array}{c}\text { Sample } 3 \\
\text { normal } \\
\end{array}$ & $\begin{array}{l}\text { Sample } 4 \\
\text { asphyxia }\end{array}$ & $\begin{array}{l}\text { Norm } v s \\
\text { asphyxia }\end{array}$ & $\begin{array}{l}\text { Before } v s \\
\text { after }\end{array}$ & Interaction \\
\hline $\begin{array}{l}\text { Indomethacin group } \\
\qquad(n=9)\end{array}$ & & & & & \multicolumn{3}{|c|}{$F$ values (degrees freedom $1 / 24$ ) } \\
\hline $\mathrm{pH}$ & $7.49 \pm 0.11$ & $7.18 \pm 0.16$ & $7.47 \pm 0.06$ & $7.11 \pm 0.19$ & $119.2^{*}$ & 2.1 & 0.8 \\
\hline $\mathrm{PCO}_{2}$ & $31 \pm 7$ & $63 \pm 6$ & $33 \pm 8$ & $63 \pm 6$ & $464.2^{*}$ & 0.0 & 0.3 \\
\hline $\mathrm{PO}_{2}$ & $78 \pm 14$ & $44 \pm 6$ & $81 \pm 11$ & $43 \pm 8$ & $188.9^{*}$ & 0.3 & 0.4 \\
\hline Blood pressure & $73 \pm 12$ & $80 \pm 14$ & $71 \pm 11$ & $83 \pm 10$ & $18.0^{*}$ & 0.1 & 1.1 \\
\hline $\begin{array}{l}\text { Placebo time-control } \\
\text { group }(n=6)\end{array}$ & & & & & \multicolumn{3}{|c|}{$F$ values (degrees freedom $1 / 15$ ) } \\
\hline $\mathrm{pH}$ & $7.51 \pm 0.05$ & $7.21 \pm 0.05$ & $7.47 \pm 0.10$ & $7.18 \pm 0.04$ & $148.0^{*}$ & 1.4 & 0.1 \\
\hline $\mathrm{PCO}_{2}$ & $35 \pm 4$ & $69 \pm 11$ & $36 \pm 7$ & $66 \pm 6$ & $190.2^{*}$ & 0.2 & 0.7 \\
\hline $\mathrm{PO}_{2}$ & $81 \pm 9$ & $47 \pm 4$ & $71 \pm 10$ & $44 \pm 5$ & $180.6^{*}$ & $6.6 \dagger$ & 1.9 \\
\hline Blood pressure & $82 \pm 17$ & $85 \pm 13$ & $78 \pm 11$ & $82 \pm 11$ & 2.1 & 1.2 & 0.0 \\
\hline
\end{tabular}

$* p<0.001$.

$\dagger p<0.025$.

reported in the present study in piglets. For example, in term, human newborns, umbilical cord arterial $\mathrm{N}$ and $\mathrm{E}$ levels after the stress of normal labor and delivery are $\simeq 4000$ and $650 \mathrm{pg} /$ $\mathrm{ml}$, respectively (5). In premature humans, cord arterial levels are $\simeq 5700$ and $600 \mathrm{pg} / \mathrm{ml}$ for $\mathrm{N}$ and $\mathrm{E}$, respectively (16). In the near-term fetal lamb, moderate hypoxemia (7-14 $\mathrm{mm} \mathrm{Hg}$ ) results in arterial levels of $\simeq 3000$ and $850 \mathrm{pg} / \mathrm{ml}$ for $\mathrm{N}$ and $\mathrm{E}$, respectively (17). Thus, $\mathrm{N}$ is the predominant catecholamine measured in the arterial circulation in response to moderate stress in the perinatal period. D levels of $500-750 \mathrm{pg} / \mathrm{ml}$, which are similar to those measured in the present study, have been reported in two recent studies of stressed human newborns $(18,19)$. Results of exogenous $D$ infusions in neonatal lambs suggest that these levels are probably not hemodynamically significant (20).

The source of catecholamines in the neonatal circulation is uncertain. Comline and Silver $(21,22)$ have described the prenatal developmental changes in the control of hypoxia-induced adrenal release of $\mathrm{N}$ and $\mathrm{E}$. Initially, the adrenal gland is not innervated and responds directly to severe hypoxia in the fetus with a predominant output of $\mathrm{N}$. As development proceeds, innervation of the gland occurs, and moderate hypoxia results in nerve stimulation-mediated release of catecholamines, with an increasing proportion being $\mathrm{E}$. In the lamb, innervation of the adrenal begins at $\simeq 120$ days gestation (of $\simeq 140$ days term gestation), while in the calf nerve stimulation-mediated release of catecholamines from the adrenal does not begin to develop until after birth. Despite the differences in timing in various species, a significant proportion of the catecholamines released from the adrenal gland in the neonate is $\mathrm{N}$. Thus, it is conceivable that the adrenal medulla is the primary source of the circulating catecholamines measured in the present study. However, spillover from postganglionic sympathetic neurons innervating vascular smooth muscle is another possible source of circulating $\mathrm{N}$.

Experiments in several in vitro systems suggest that prostaglandins are involved in a negative feedback loop which modulates $\mathrm{N}$ release from adrenergic neurons (3). According to this model, when $N$ binds to the postsynaptic $\alpha$-adrenergic receptor and causes smooth muscle constriction, prostaglandins are released, which diffuse back to the adrenergic nerve ending and attenuate the further release of $N$. Initial work in several perfused organs such as cat spleen, rabbit heart, kidney, and ear, and isolated vessels from cat and man suggested that the responsible prostaglandin was $\mathrm{PGE}_{2}(3,23)$. More recent work in the perfused rat heart and isolated vessels suggests that $\mathrm{PGI}_{2}$ also may be involved $(24,25)$. In the various tissues in which this system has been described, IND and other cyclooxygenase inhibitors cause an augmented release of $\mathrm{N}$ in response to nerve stimulation, presumably by preventing or reducing the prostaglandin-mediated atten- uation of $\mathrm{N}$ release. Furthermore, adrenal release of catecholamines during hemorrhage is augmented by IND although the mechanism of this finding is unclear (4).

As noted above, the predominance of $\mathrm{N}$ in the neonatal response to stress suggests that spillover from postganglionic sympathetic neurons innervating vascular smooth muscle may be a significant source of circulating $\mathrm{N}$ in the newborn. This possibility, along with the observation of indomethacin-induced augmentation of adrenal catecholamine release, suggests that inhibition of the prostaglandin-mediated feedback loop would result in significant elevation of circulating $\mathrm{N}$ measured in response to asphyxia in the neonate.

However, in the present study, IND did not increase either baseline levels of catecholamines or those measured after $20 \mathrm{~min}$ of breathing $10 \% \mathrm{O}_{2} / 9 \% \mathrm{CO}_{2}$. Other investigators, employing adult models, have also failed to demonstrate increased circulating catecholamine levels in response to $\operatorname{IND}(26,27)$.

There are several possibilities that could explain the failure of IND to increase catecholamine levels in the present study. First, augmentation of nerve stimulation-induced release of $\mathrm{N}$ by IND has not been found universally; there are clearly tissue and species differences (28-30). Thus, in the neonatal piglet it is possible that prostaglandins play no role in the control of catecholamine release. A second possibility in the neonatal piglet is that prostaglandin-mediated feedback is involved in the local regulation of adrenergic neurotransmission in some vascular beds but that this mechanism is not universal and/or does not modulate adrenal release of catecholamines. Third, it is conceivable that IND did augment catecholamine release in the present study but that the neuronal and endothelial reuptake mechanisms prevented an increase in the circulating levels. The results of this study suggest that prostaglandins, whether or not they are involved in the local regulation of sympathetic neurotransmission, do not modulate the circulating levels of catecholamines seen in response to asphyxia in the neonatal piglet.

The failure of asphyxia to increase significantly the arterial pressure in the time-control piglets is unlikely to have affected these results since IND had no significant effect in the treatment group. This occurred because one of the time-control piglets developed significant hypotension in response to both asphyxial challenges. Similarly, the small but statistically significant decrease in arterial $\mathrm{PO}_{2}$ during the second period in the timecontrol animals is unlikely to have altered the observations.

\section{SUMMARY}

In the present study, neonatal piglets exposed to $10 \% \mathrm{O}_{2} / 9 \%$ $\mathrm{CO}_{2}$ for 20 min developed marked elevation of circulating levels 
of $\mathrm{D}, \mathrm{E}$, and $\mathrm{N}$. Administration of the prostanoid synthesis inhibitor IND did not alter either baseline levels of catecholamines or the change in levels observed with asphyxia. These results argue against a role for prostaglandins in the modulation of the circulating catecholamine response of the neonate to a global stress such as asphyxia.

\section{REFERENCES}

1. McCarthy JA 1978 Prostaglandins: an overview. Adv Pediatr 25:12-149

2. Lagercrantz H 1983 The development and functional role of the sympathoadrenal system in the newborn. In: Stern L, Bard H, Friis-Hansen B (eds) Intensive Care in the Newborn IV. Masson, New York, pp 67-75

3. Hedqvist P 1977 Basic mechanisms of prostaglandin action on autonomic neurotransmission. Ann Rev Pharmacol Toxicol 17:259-279

4. Feuerstein N, Feuerstein G, Gutnam Y 1979 Endogenous prostaglandins modulate adrenal catecholamine secretion. Eur J Pharmacol 58:489-492

5. Eliot RJ, Lam R, Leake RD, Hobel CJ, Fisher DA 1980 Plasma catecholamine concentrations in infants at birth and during the first 48 hours of life. $J$ Pediatr 96:311-315

6. Kaapa P, Viinikka L, Ylikorkala O 1982 Plasma prostacyclin from birth to adolescence. Arch Dis Child 57:459-461

7. Green RS, Leffler CW 1984 Hypoxia stimulates prostacyclin synthesis by neonatal lungs. Pediatr Res 18:832-835

8. Leffler CW, Busija DW, Fletcher AM, Beasley DG, Hessler JR, Green RS 1985 Effects of indomethacin upon cerebral hemodynamics of newborn pigs. Pediatr Res 19:1160-1164

9. Leffler CW, Busija DW 1985 Prostanoids in cortical subarachnoid cerebrospinal fluid and pial arterial diameter in newborn pigs. Circ Res 57:689-694

10. Zaritsky A, Chernow B 1984 Use of catecholamines in pediatrics. J Pediatr 105:341-350

11. Friedman WF, Hirschklau MJ, Printz MP, Pitlick PT, Kirkpatrick SE 1976 Pharmacologic closure of patent ductus arteriosus in the premature infant. N Engl J Med 295:526-529

12. Neutze JM, Starling MB, Elliott RB, Barratt-Boyes BG 1977 Palliation of cyanotic congenital heart disease in infancy with E-type prostaglandins. Circulation 55:238-241

13. Peuler JD, Johnson GA 1977 Simultaneous single isotope radioenzymatic assay of plasma norepinephrine, epinephrine and dopamine. Life Sci 21:625636

14. Padbury JF, Diakomanolis ES, Hobel CJ, Perelman A, Fisher DA 1981
Neonatal adaptation: sympatho-adrenal response to umbilical cord cutting Pediatr Res 15:1483-1487

15. Kirk RE 1982 Experimental Design. Brooks/Cole, Belmont, CA, pp 443-446

16. Newnham JP, Marshall CL, Padbury JF, Lam RW, Hobel CJ, Fisher DA 1984 Fetal catecholamine release with preterm delivery. Am J Obstet Gynecol 149:888-893

17. Cohen WR, Piasecki GJ, Jackson BT 1982 Plasma catecholamines during hypoemia in fetal lamb. Am J Physiol 243:R520-R525

18. Padbury J, Agata Y, Ludlow J, Polk D, Goldblatt E, Pescetti J 1986 Dopamine pharmacokinetics in critically ill newborns. Pediatr Res 20:207A (abstr)

19. Polak MJ, Liechty A 1986 Plasma dopamine, epinephrine, and norepinephrine levels in premature neonates: response to constant dopamine infusion. Pediatr Res 20:208A(abstr)

20. Felfes TF, Hansen TN, Martin CG, LeBlanc A, Smith S, Giesler M 1986 Effects of dopamine on cardiac output and regional blood flow in lambs. Pediatr Res 20:203A(abstr)

21. Comline RS, Silver M 1961 The release of adrenaline and noradrenaline from the adrenal glands of the foetal sheep. J Physiol 156:424-444

22. Comline RS, Silver M 1966 Development of activity in the adrenal medulla of the foetus and newborn animal. Br Med Bull 22:16-20

23. Hedqvist $P 1977$ Prostaglandins as modulators of autonomic neuroeffector transmission. In: Berti F, Samuelsson B, Velo GP (eds) Prostaglandins and Thromboxanes. Plenum, New York, pp 423-432

24. Golub MS, Berger ME, Powell M 1985 Adrenergic stimulation of prostacyclin production in the rat tail artery. I. Response to agonists and antagonists. Prostaglandins Leukotrienes Med 20:299-311

25. Khan MT, Malik KU 1982 Modulation by prostaglandins of the release of $\left[{ }^{3} \mathrm{H}\right]$ noradrenaline evoked by potassium and nerve stimulation in the isolated rat heart. Eur J Pharmacol 78:213-218

26. Rubin P, Blaschke T 1979 Plasma catecholamines in man are not influenced by the inhibition of prostaglandin synthesis. Prostaglandins 17:581-585

27. Gullner HG, Lake CR, Bartter FC, Kafka MS 1979 Effect of inhibition of prostaglandin synthesis on sympathetic nervous system function in man. J Clin Endocrinol Metab 49:552-556

28. Malik KU, McGiff J 1975 Modulation by prostaglandins of adrenergic transmission in the isolated perfused rabbit and rat kidney. Circ Res 36:599-609

29. Malik KU, Ryan P, McGiff JC 1976 Modification by prostaglandins $E_{1}$ and $\mathrm{E}_{2}$, indomethacin, and arachidonic acid of the vasoconstrictor responses of the isolated perfused rabbit and rat mesenteric arteries to adrenergic stimuli. Circ Res 39:163-168

30. Malik KU 1978 Prostaglandin-mediated inhibition of the vasoconstrictor responses of the isolated perfused rat splenic vasculature to adrenergic stimuli. Circ Res 43:225-233 